\title{
Steinstrasse predictive factors and outcomes after extracorporeal shockwave lithotripsy
}

\author{
Jarques Lucio II, Fernando Korkes, Antonio Corrêa Lopes-Neto, Edward Gomes Silva, \\ Mário Henrique Elias Mattos, Antonio Carlos Lima Pompeo
}

Division of Urology, ABC Medical School, Santo André-SP, Brazil

\begin{abstract}
Purpose: Urinary stone disease is a common medical problem. Extracorporeal shockwave lithotripsy (SWL) has been applied with high success and low complication rates. Steinstrasse (SS) is a possible complication after SWL. The aim of the present study was to prospectively evaluate the factors and outcomes associated with SS after SWL.

Materials and Methods: We have prospectively evaluated 265 SWL sessions (2005-2009). Two lithotriptors were used randomly: Siemens Lithostar and Dornier Compact S. All patients had imaging exams after 30 and 90 days or according to symptoms.

Results: SS was observed in $14(5.3 \%)$ out of 265 SWL procedures $(n=175$ patients, $51.5 \%$ women $/ 48.5 \%$ men, mean $\pm \mathrm{SD}$ age $=46.3 \pm 15.5$ years). SS was more common after SWL for pelviureteral calculi rather than caliceal stones $(\mathrm{p}=$ 0.036). There was a trend toward more occurrences of SS after SWL for larger stone area $\left(>200 \mathrm{~mm}^{2}, \mathrm{p}=0.072\right)$. Preoperative ureteral stent didn't prevent SS. SWL machine, intensity, number of pulses and frequency were not associated with SS formation. Post-SWL pain, fever and gravel elimination were factors associated with $S S(p=0.021 ; p=0.011 ; p$ $=0.078$ ). When SS occurred, treatment modalities included Medical Expulsive Therapy (MET), ureteroscopy and SWL. Conclusions: Steinstrasse is an uncommon event after SWL and seems to occur more frequently with larger pelviureteral stones. Impaction of stones is more frequent in the middle ureter. All patients should be followed after SWL, but SS should be specially suspected if there is macroscopic gravel elimination, flank pain and/or fever. When SS occurs, treatment should be promptly introduced, including medical expulsive therapy, surgical approach or SWL in selected cases. Further prospective studies are awaited to evaluated preventive measures for SS occurrence.
\end{abstract}

Key words: Urinary calculi; Lithotripsy; Ureteral Obstruction; treatment outcome; adverse effects

Int Braz J Urol. 2011; 37: 477-482

\section{INTRODUCTION}

Urinary stone disease is a common medical problem in the general population. Extracorporeal Shock Wave Lithotripsy (SWL) has been introduced as a revolutionary therapy to break up stones through shock waves, representing a minimally invasive therapy, with high success and low complication rates. Third generation SWL machines became more compact; treatments became less painful and SWL sessions became more comfortable. However, compli- cations can occur in $3-12 \%$ of cases, including pain, steinstrasse, need for auxiliary procedures, hematuria and hematomas $(1,2)$. Less frequently, fever, hydronephrosis and sepsis may occur (3). Steinstrasse (SS) is a complication defined as the presence of more than one ureteral stone simultaneously, and occur in 1.1 to $24.2 \%$ of patients after SWL $(2,4-6)$. To the best of our knowledge, factors associated with SS occurrence have never been prospectively evaluated. The aim of the present study was to prospectively evaluate the factors associated with SS after SWL and outcomes of SS treatment. 


\section{MATERIALS AND METHODS}

We have prospectively evaluated 1456 SWL sessions at our institution. Procedures were performed as outpatient basis between January 2005 and January 2009. A 6-hour fasting and bowel preparation was recommended, and procedures were performed with monitored sedation (Midazolan and Fentanyl). Patients who underwent SWL at our institution but whose follow-up was done by other physicians were excluded from the present study. Patients without adequate follow-up (at least two office visits after SWL session) have also been excluded from further analysis. After excluding these patients, a total of 265 SWL sessions were analyzed. Stone composition or density on CT scans was not routinely assessed in the present study, as imaging studies included simple flat plate of abdomen (KUB), ultrasound or CT scan prior treatment.

Two lithotriptors (Siemens Lithostar or Dornier Compact S) were used randomly, according to date of scheduled procedure in our medical insitutions. During SWL sessions, stones were located either through ultrasound and/or fluoroscopy. All patients were followed with image exams (KUB, ultrasound or CT scan) after 30 and 90 days from treatment sessions, or according to symptoms. Even though SS can occur earlier and transiently after SWL, the present protocol was designed to diagnose clinically significant SS.

Shock waves intensity were progressively increased, and a maximum of 4,000 and 5,000 pulses were respectively applied for renal and ureteral calculi (mean $\pm \mathrm{SD}=4397 \pm 689$ pulses Rate $=116 \pm$ $10 \mathrm{pulses} / \mathrm{min}$; intensity $=4.2 \pm 1.8$ ). Ureteral stents were placed prior to SWL procedures for larger stones $(>2.0 \mathrm{~cm})$ or patients with solitary kidneys.

All patients have signed an informed consent and institutional review board has approved the present study. Statistical analysis was performed using the Statistical Package for Social Sciences software (SPSS 13.0 for Mac OS X, SPSS, Inc., Chicago, Illinois). Complications were analyzed with the Pearson chi-square test, and parametric measures using $T$ test. Statistical significance was determined at $\mathrm{p}<0.05$.

\section{RESULTS}

Of the 1456 SWL procedures performed during this period of time, 952 SWL sessions were performed in patients $(65.4 \%)$ that followed up elsewhere and were excluded from further analysis. According to our exclusion criteria we identified 239 patients (16.4\%), who had incomplete follow-up. A total of $265 \mathrm{SWL}$ procedures applied to 175 patients $(51.5 \%$ women / $48.5 \%$ men, mean $\pm \mathrm{SD}$ age $=46.3 \pm 15.5$ years, range 13-81 years, see Table-1), were analyzed. SS was observed in $5.28 \%(\mathrm{n}=14)$ of procedures. SS occurred in mid ureter $(42.9 \%, \mathrm{n}=6)$, lower ureter $(35.7 \%, \mathrm{n}=5)$ and upper ureter $(21.4 \%, \mathrm{n}=3)$. A statistical comparison was made between these patients who presented SS and those who did not. Both groups had similar gender and age (Table-1).

Pelviureteral calculi had significantly been more associated with SS than caliceal stones. Placement of a preoperative ureteral stent did not prevent SS occurrence (Table-1). Additionally, SWL machine, intensity, number of pulses, frequency, fluoroscopy time, immediate post-SWL result or haematuria was not associated with SS formation (Table-2).

Post-SWL pain and fever were factors associated with the occurrence of SS, as occurrence of SS was more frequent when gravel elimination was observed (Table-2). Moreover, SS occurred often after SWL when large stone burden was identified by radiographic area, even if patients had a lower number of stones (Tables 1 and 3).

When SS occurred, treatment modalities applied included medical expulsive therapy, analgesics, anti-inflammatories and alpha-blockers (40\%), ureteroscopy (34.3\%) and SWL (25.7\%). Treatment modalities were determined according to clinical judgment and after discussing options with the patient. SWL or ureteroscopy were performed for larger stone fragments, calculi determining moderate/severe hydronephrosis, when infection was suspected, with severe and untreatable pain or for patients who refused to undergo medical expulsive therapy. All procedures were performed successfully. 
Table 1 - Patients'demographics and peri-operative data $(n=265)$.

\begin{tabular}{|c|c|c|c|c|}
\hline & SS & No-SS & total & \\
\hline Characteristic & Mean \pm SD & Mean \pm SD & Mean \pm SD & $\mathbf{p}$ \\
\hline Age (years) & $49.1 \pm 17.4$ & $46.1 \pm 15.5$ & $46.3 \pm 15.5$ & 0.449 \\
\hline Stone area $\left(\mathrm{mm}^{2}\right)$ & $129.3 \pm 80.0$ & $95.8 \pm 74.9$ & $97.6 \pm 75.2$ & 0.246 \\
\hline \multirow[t]{2}{*}{ Number of stones } & $1.2 \pm 0.6$ & $1.5 \pm 1.0$ & $1.5 \pm 0.9$ & $0.037 *$ \\
\hline & $\%(n)$ & $\%(n)$ & $\%$ (n) & \\
\hline Gender & & & & 0.176 \\
\hline Male & $6.2(8)$ & $93.8(121)$ & 48.7 (129) & \\
\hline Female & $4.4(6)$ & $95.6(130)$ & $51.3(136)$ & \\
\hline Stone location & & & & $0.036^{*}$ \\
\hline Caliceal & $3.0(5)$ & $97.0(163)$ & $168(63.4)$ & \\
\hline Pelviureteral & $8.8(9)$ & $91.2(88)$ & $97(38.5)$ & \\
\hline Side & & & & 0.478 \\
\hline Right & $4.3(6)$ & 95.7 (132) & $52.1(138)$ & \\
\hline Left & $6.3(8)$ & 93.7 (119) & $47.9(127)$ & \\
\hline Prior ureteral stent & $28.6(4)$ & $17.9(45)$ & $18.5(49)$ & 0.318 \\
\hline
\end{tabular}

$S S=$ steinstrasse $; X=$ average $; S D=$ standard deviation; $p$ value by $T$ Test and chi-square test

\section{DISCUSSION}

Overall incidence of SS after SWL procedures was of $5.3 \%$, similar to other series (4.0$8.2 \%)(6,7)$. However certain factors that had never been previously studied could be better evaluated, and our study has some important findings.

First, we have observed that SS is an uncommon event after SWL, and occurs after 5.3\% of procedures. If we consider the high prevalence of urinary stone disease and the number of these patients who undergo SWL, its occurrence becomes epidemiologically significant. We have observed that stones stop more frequently in the middle ureter.

Second, SS occurred more frequently when SWL was applied to stones located in the pelviureteral complex rather than caliceal stones. It makes sense that when SWL is efficient in pelviureteral stones, more fragments can migrate simultaneously, when compared to caliceal stones, and other authors have also demonstrated this fact
(7). SS occurred more frequently when there were more stones $(p=0.037)$. There was a trend towards more occurrence of SWL for stones with larger areas, mainly $>200 \mathrm{~mm}^{2}(\mathrm{p}=0.072$, Table-3). Even in cases with a larger number of stones, this trend was observed, as previously reported $(5,7)$. When treating patients with an increased risk of $\mathrm{SS}$, as those with large pelvic stones, preventive treatment for SS such as alpha-blockers could be prescribed (8-10). Further studies should be conduced to evaluate its effects.

Third, epidemiological factors as patient age, gender, kidney side as well as session characteristics (lithotriptor, intensity, frequency, pulses) are not associated with SS occurrence. It has been demonstrated that children eliminate easier and faster stone fragments after SWL (11), leading to lower SS occurrence rates (12). However, as we have treated mostly adults this data could not be confirmed in our study. Previous placement of a double J stent has not prevented SS occurrence, as observed by other authors (13). However, ureteral 
Table 2 - Treatment and post-treatment outcomes associated with SS.

\begin{tabular}{|c|c|c|c|c|}
\hline & $\begin{array}{c}\text { No SS } \\
(\mathrm{n}=\mathbf{2 4 1})\end{array}$ & $\begin{array}{c}\text { SS } \\
(n=14)\end{array}$ & $\begin{array}{l}\text { TOTAL } \\
(\mathrm{n}=\mathbf{2 6 5})\end{array}$ & $\mathbf{p}$ \\
\hline & $\%(n)$ & $\%(n)$ & $\%(n)$ & \\
\hline SWL machine & & & & 0.290 \\
\hline Dornier & $95.9(142)$ & $4.1(6)$ & & \\
\hline Siemens & $93.0(106)$ & $7.0(8)$ & & \\
\hline Imm.treatment impression & & & & 0.414 \\
\hline Unchanged & $100.0(23)$ & $0(0)$ & $8.7(23)$ & \\
\hline Mildly Changed & 94.7 (177) & $5.3(10)$ & $70.6(187)$ & \\
\hline Changed & $92.6(50)$ & $7.4(4)$ & $20.4(54)$ & \\
\hline Macro. Gravel elimination & $63.3(159)$ & $85.7(12)$ & $64.5(171)$ & 0.078 \\
\hline Haematuria & $66.1(166)$ & $85.7(12)$ & $67.2(178)$ & 0.129 \\
\hline Pain & $54.2(136)$ & $85.7(12)$ & $55.8(148)$ & $0.021 *$ \\
\hline \multirow[t]{2}{*}{ Fever } & $2.4(6)$ & $14.3(2)$ & $3.0(8)$ & $0.011 *$ \\
\hline & $\mathbf{X} \pm \mathbf{S D}$ & $\mathbf{X} \pm \mathbf{S D}$ & $\mathbf{X} \pm \mathbf{S D}$ & $\mathbf{p}$ \\
\hline Intensity & $3.7 \pm 1.75$ & $4.2 \pm 1.8$ & $4.2 \pm 1.8$ & 0.265 \\
\hline No. of pulses & $4303.6 \pm 554.2$ & $4404.6 \pm 697.4$ & $4397.8 \pm 689.2$ & 0.176 \\
\hline Frequency & $116.4 \pm 9.3$ & $116.8 \pm 10.2$ & $116.8 \pm 10.1$ & 0.883 \\
\hline Fluoroscopy time & $2.7 \pm 1.7$ & $2.3 \pm 1.1$ & $2.7 \pm 1.6$ & 0.234 \\
\hline Analgesic dose & $4.7 \pm 1.8$ & $5.7 \pm 1.5$ & $4.8 \pm 1.8$ & 0.187 \\
\hline Immediate pain & $1.7 \pm 1.3$ & $2.0 \pm 1.4$ & $1.7 \pm 1.3$ & 0.215 \\
\hline
\end{tabular}

$S S=$ steinstrasse $; X=$ average $; S D=$ standard deviation; $p$ value by $T$ Test and chi-square test

stents were placed selectively, patients with larger stones with potential increased risk for complications. This approach is currently controversial, being recommended for stones from 1.5-3.5 cm (5), larger than $2.0 \mathrm{~cm}(13)$ or only for stones larger than $2.5 \mathrm{~cm}$ (14) according to different authors. We found that patients with large stones with pre-placement of ureteral stents did not prevent SS occurrence after SWL, but it can minimize SS symptoms.

Fourth, occurrence of symptoms after SWL was associated with SS. Flank pain and fever occurrence were associated with a 5.3 and 3.5 fold risk of diagnosing SS after an SWL session $(\mathrm{p}=0.021 ; \mathrm{p}=0.011)$. When macroscopic gravel elimination was noted there was also a trend toward a higher rate of SS $(p=0.078)$. These patients should be carefully investigated and treated to avoid short and long-term complications.

Fifth, in our experience almost $60 \%$ of patients with SS required a surgical approach to treat this complication. SWL or ureteroscopy were performed for larger stone fragments, calculi causing moderate/severe hydronephrosis, when infection was suspected, with severe and untreatable pain or who refused to undergo medical expulsive therapy (15-17). 
Table 3 - SS occurrence after SWL according to stone area.

\begin{tabular}{lcccc}
\hline & SS & No-SS & total \\
\hline Stone Área $\left(\mathbf{m m}^{2}\right)$ & \% (n) & \% (n) & \% (n) & $100(166)$ \\
$0-100$ & $3.6(6)$ & $96.4(160)$ & $100(80)$ \\
$101-200$ & $6.2(5)$ & $93.8(75)$ & $100(19)$ \\
$>200$ & $15.8(3)$ & $84.2(16)$ & $\mathbf{p}$ \\
\hline
\end{tabular}

SS occurrence after SWL according to stone area.

Our study has some limitations. First, since this is an uncommon event, the number of patients with SS was relatively small, what limits the power of the study. Also, we have excluded from further analysis patients who lost to follow-up. We believe that this could overestimate the occurrence of SS, since asymptomatic patients would be more prone to lose follow-up. Another interesting aspect would be stone composition or density on CT scans, but these data could not be assessed in the present study. However, these flaws do not diminish the value of the present study, they raise questions for further investigations.

In conclusion, SS is an uncommon event after SWL and seems to occur more frequently with larger pelviureteral stones. SS occurs more frequently at mid ureter. All patients should be followed after an SWL session, but SS should be especially suspected if there is the perception of macroscopic gravel elimination, flank pain and/or fever. When SS occurs treatment should be promptly introduced, including medical expulsive therapy, surgical approach (ureteroscopy or ureteral stent placement) or SWL session according to clinical judgment. Further prospective studies are awaited to evaluated preventive measures for SS occurrence.

\section{CONFLICT OF INTEREST}

None declared.

\section{REFERENCES}

1. Kostakopoulos A, Stavropoulos NJ, Macrychoritis C, Deliveliotis C, Antonopoulos KP, Picramenos D: Subcapsular hematoma due to ESWL: risk fac- tors. A study of 4,247 patients. Urol Int. 1995; 55: 21-4.

2. Salem S, Mehrsai A, Zartab H, Shahdadi N, Pourmand G: Complications and outcomes following extracorporeal shock wave lithotripsy: a prospective study of 3,241 patients. Urol Res. 2010; 38: $135-42$.

3. Quintero Mdel S, Alvarez UM, Wacher C, Gutiérrez J, Castaño-Tostado E, Fernández F, et al.: Interaction of shockwaves with infected kidney stones: is there a bactericidal effect? J Endourol. 2008; 22: 1629-37.

4. Sayed MA, el-Taher AM, Aboul-Ella HA, Shaker SE: Steinstrasse after extracorporeal shockwave lithotripsy: aetiology, prevention and management. BJU Int. 2001; 88: 675-8.

5. Al-Awadi KA, Abdul Halim H, Kehinde EO, AlTawheed A: Steinstrasse: a comparison of incidence with and without $\mathrm{J}$ stenting and the effect of J stenting on subsequent management. BJU Int. 1999; 84: 618-21.

6. Madbouly K, Sheir KZ, Elsobky E, Eraky I, Kenawy M: Risk factors for the formation of a steinstrasse after extracorporeal shock wave lithotripsy: a statistical model. J Urol. 2002; 167: 1239-42.

7. Soyupek S, Armagan A, Kosar A, Serel TA, Hoscan MB, Perk H, et al.: Risk factors for the formation of a steinstrasse after shock wave lithotripsy. Urol Int. 2005; 74: 323-5.

8. Agarwal MM, Naja V, Singh SK, Mavuduru R, Mete UK, Kumar S, et al.: Is there an adjunctive role of tamsulosin to extracorporeal shockwave lithotripsy for upper ureteric stones: results of an open label randomized nonplacebo controlled study. Urology. 2009; 74: 989-92.

9. Gravas S, Tzortzis V, Karatzas A, Oeconomou A, Melekos MD: The use of tamsulozin as adjunctive treatment after ESWL in patients with distal ureteral stone: do we really need it? Results from a randomised study. Urol Res. 2007; 35: 231-5. 
10. Kobayashi M, Naya Y, Kino M, Awa Y, Nagata M, Suzuki H, et al.: Low dose tamsulosin for stone expulsion after extracorporeal shock wave lithotripsy: efficacy in Japanese male patients with ureteral stone. Int J Urol. 2008; 15: 495-8.

11. Sternberg K, Greenfield SP, Williot P, Wan J: Pediatric stone disease: an evolving experience. J Urol. 2005; 174: 1711-4; discussion 1714.

12. Shokeir AA, Sheir KZ, El-Nahas AR, El-Assmy AM, Eassa W, El-Kappany HA: Treatment of renal stones in children: a comparison between percutaneous nephrolithotomy and shock wave lithotripsy. J Urol. 2006; 176: 706-10.

13. Mohayuddin N, Malik HA, Hussain M, Tipu SA, Shehzad A, Hashmi A, et al.: The outcome of extracorporeal shockwave lithotripsy for renal pelvic stone with and without JJ stent--a comparative study. J Pak Med Assoc. 2009; 59: 143-6.

14. Mustafa M, Ali-El-Dein B: Stenting in extracorporeal shockwave lithotripsy; may enhance the passage of the fragments! J Pak Med Assoc. 2009; 59: 141-3.

15. Korkes F, Lopes-Neto AC, Mattos MH, Pompeo AC, Wroclawski ER: Patient position and semirigid ureteroscopy outcomes. Int Braz $\mathrm{J}$ Urol. 2009; 35: 542-7; discussion 548-50.
16. Korkes F, Gomes SA, Heilberg IP: Diagnosis and Treatment of Ureteral Calculi. J Bras Nefrol. 2009; 31: 55-61.

17. Turk C, Knoll T, Petrik A, Sarica K, Seitz C, Straub M, et al.: Guidelines on urolithiasis. European Association of Urology. 2010. [Last accessed September 08, 2010]. Avaliable at: http://www. uroweb.org/gls/pdf/Urolithiasis\%202010.pdf

Submitted for publication:

July 27, 2010

Accepted after revision:

January 11, 2011

\section{Correspondence address:}

Dr. Fernando Korkes

Rua Pirapora, 167

São Paulo, SP, 04008-060, Brazil

Email: fkorkes@terra.com.br 